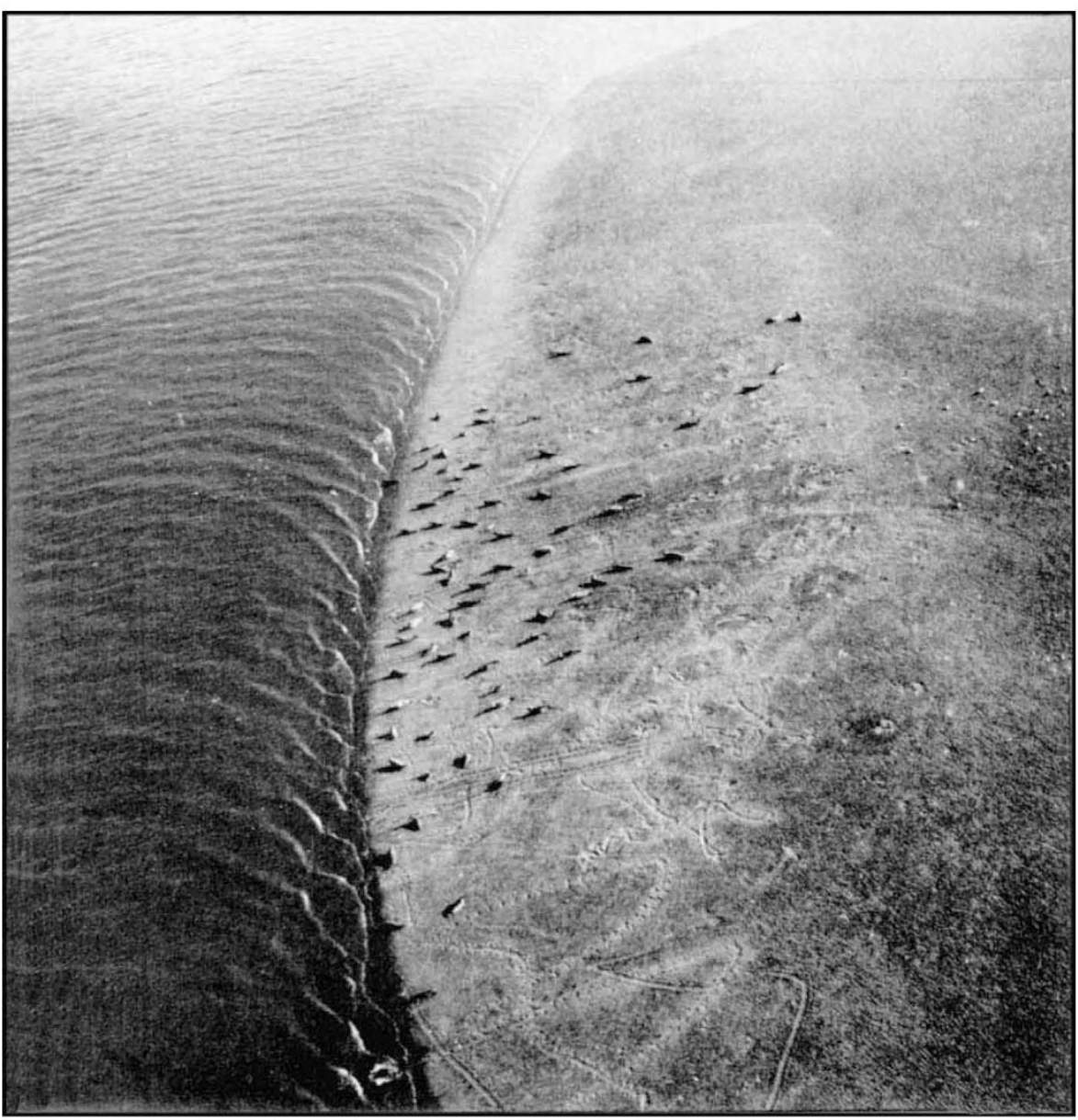

\title{
Counting the Common Seal
}

How many Common Seals are there in the Wash? Is the population in danger of extinction? Conflicting estimates of the size of this stock have attracted considerable public attention since the Home Secretary refused to grant hunting licences in 1974 in spite of the fact that 400 could legally be culled under the Conservation of Seals Act 1970. Dr C. F. Summers of the Seals Research Division (SRD) of the Institute for Marine Environmental Research and $\operatorname{Dr}$ M. D. Mountford of the Institute of Terrestrial Ecology, both of the Natural Environment Research Council, explain the basis on which population estimates are made.

THE seal biologist does not have access to samples representative of whole populations in the same way that a fish biologist might, because commercial sealing in Britain concentrates almost exclusively on seal pups which provide high quality skins for the fur trade. It is, therefore, difficult to estimate the size of seal stocks directly.

This problem is usually surmounted by measuring some index of the population, such as the number of pups born annually. This is useful for identifying trends in stock size and, if adequate life-table data for the species are available from another source, it is possible to convert pup production to an allage estimate (assuming that the life table parameters have similar values in both stocks).

If we consider the problem of obtaining an estimate of annual pup production, the Common Seal, Phoca vitulina vitulina, presents peculiar difficulties. Unlike the Grey Seal, Halichoerus grypus, it does not congregate into recognisable breeding assemblies, nor do the pups remain on land for more than a few hours after birth. Direct counting of pups does not, therefore, yield realistic estimates of production. Nevertheless, this is all that can be attempted in some localities and the best information obtainable is a minimum estimate of productivity.

In the Wash, however, where pups are relatively easy to catch for tagging and where the commercial hunters have cooperated by returning the tags, it has been possible to obtain a more realistic estimate of pup production than elsewhere. Before describing this it is interesting to consider earlier attempts to measure the size of the Common Seal stock in the Wash.

Counts of Common Seals hauled out on sandbanks throughout the Wash have been recorded since the 1920s. Before 1965, however, the counts did not cover the entire area. They were made by individual observers from boats and, even with a very fast boat it is not possible to visit all the sandbanks in the Wash during the period of a single low tide.

Since 1965 aerial photographic surveys have been made by the SRD at all states of tide and throughout the year, visiting all the sandbanks in a short period of time. Fluctuations in the counts made from these photographs suggest that the isolated counts of a few sandbanks made from a boat cannot be used to estimate the size of the whole population. Moreover, since is is not known what proportion of the population is hauled out at any one time the published counts from the aerial photographs do not give a correct estimate of the number of seals in the Wash. It was suggested in the 1972-73 report of the Universities Federation of Animal Welfare that only a small proportion of seals remain in the water at low tide and that as the maximum number of seals reported hauled out at any one time was 1,722 (July 17,1969 ) the population size of around 6,000 reported by the SRD must be a gross overestimate. This argument is invalidated by the very large variation in the aerial counts. For example, in February 1968 , 472 seals were counted as compared with 1,534 in March 1968. Between these two observations the population had either trebled through immigration, or a very large proportion of the seals which hauled out in March did not do so in February.

Common Seals shot in the Wash between 1911 and 1953 attracted a bounty paid by the Ministry of Agriculture, Fisheries and Food and the Eastern Sea Fisheries Committee. The animals were killed to protect local fisheries and consisted of juveniles and adults. Commercial seal hunting for the fur trade started in the Wash in the early 1960 s and large numbers of pups were taken before the passage of the Conservation of Seals Act 1970. (The Act provides protection for both Grey and Common Seals during their respective pupping seasons but also allows seals to be killed for several different purposes. Seals are killed under licence in the Wash in compliance with that section of the Act which permits "the use of a population surplus of seals as a resource.")

Between 1968 and 1973, the SRD used a capture-recapture technique to estimate Common Seal pup production in the Wash. Pups were tagged in June and early July and an estimate of pup numbers was made from the proportion of tags 'recaptured' in the hunters' 
catch, usually in the second and third weeks of July. To give a correct estimate the capture-recapture method requires certain conditions to be met. (1) The tagging and the hunting effort should be random. Older pups are more difficult to tag and shoot, but the chance of being tagged and the chance of being shot, if related at all, must be positively correlated. This has the effect of underestimating the population size.

(2) In the interval between tagging and hunting there must be no gains or losses through immigration, emigration or mortality. Immigration and emigration are not important, since pups move only short distances during the first few weeks of life. If, however, this condition is not met with regard to mortality, the capture-recapture method overestimates the population size by a factor of $1 / p$, where $p$ is the probability that a pup, alive at the time of tagging, is still alive and present in the population at the time of hunting. No precise figure of the mortality during the sampling period is available but a $21 \%$ post-natal mortality for the first year of life has been reported for $P$. vitulina richardi. Therefore, the upper limit of the degree of overestimation that could be produced by the capture-recapture method is given by assuming that the whole of this firstyear mortality occurs in the interval between tagging and hunting. If this happened the method would overestimate the population here by about $27 \%$.

(3) There must be no recruitment of pups during the 'recapture' sampling. Although this is not the case, while the method overestimates the population at the time of tagging, it gives an unbiased estimate at the time of hunting.

(4) There should be no difference in mortality between tagged and untagged pups. Since it was found that tagging did not affect the growth rate it is unlikely to have increased pup mortality.

Table 1 shows the pup production estimates calculated for the years 1968-73. There is no value for 1969 because tags were not properly returned, or for 1974 because there was no hunting. When the five years are combined, an estimate and approximate $95 \%$ confidence interval of $1,450 \pm 239$ pups is obtained. The data suggest neither an upward nor a downward trend in productivity.

Using a life-table for $P$. vitulina richardi in British Columbia compiled by M. A. Biggs (Bull. Fish. Res. Bd Can., No. 172, 1969) it is evident that the number of pups born represents about $1: 4.5$ of the total stock. The estimate obtained from this table for the all age population, that is pups,

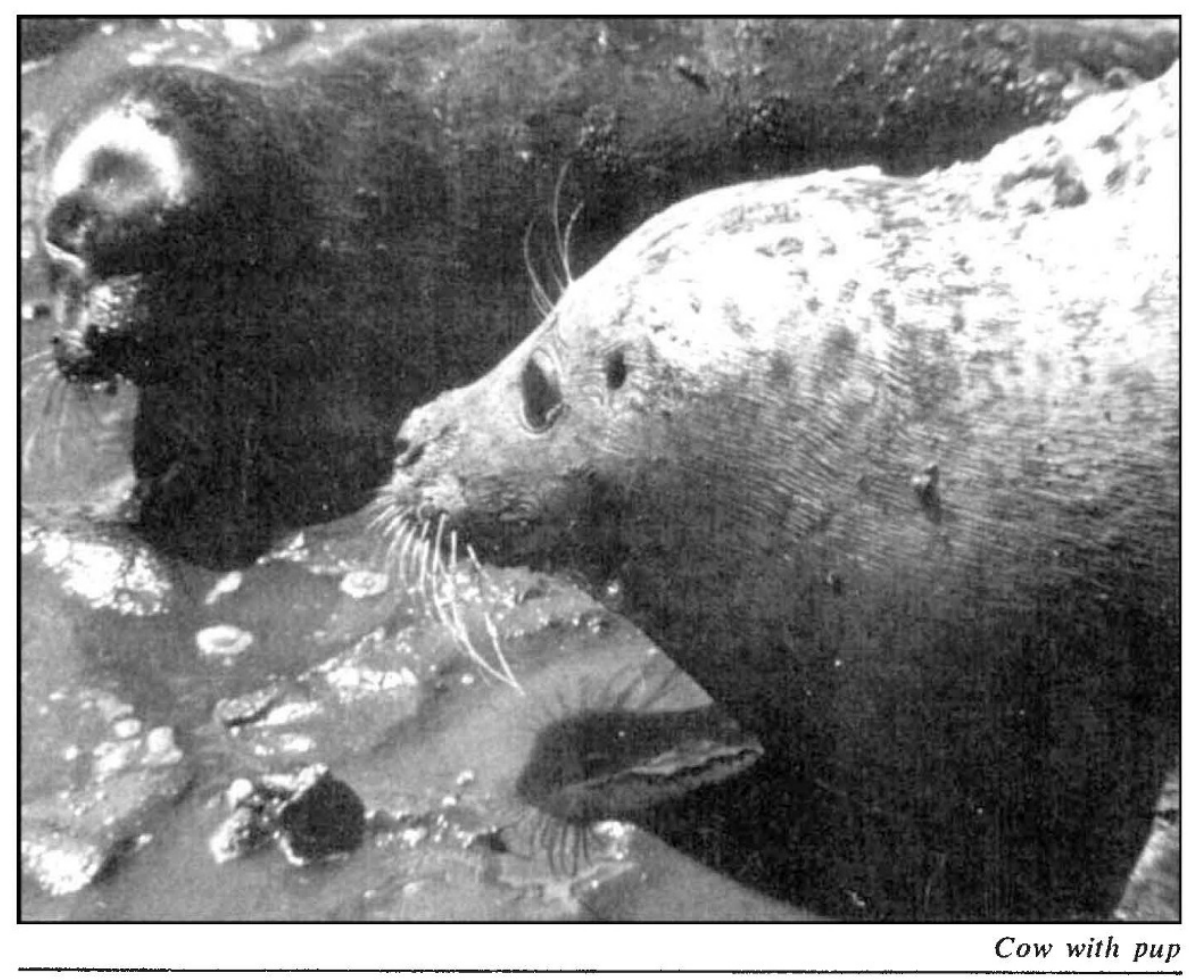

non-breeding and breeding adults, is $6,525 \pm 1,076$

We have referred to a possible overestimation by the capture-recapture technique but, considering other available evidence, it is fairly certain that during the mid-1960s the Wash population was at least 4,000 . In 1966, 850 pups were shot by commercial hunters. As it is unlikely that they ever shot an entire year class, the all-age population must have been in excess of about $3,825(850 \times 4.5)$ in 1966 . This level of hunting would take four or five years, after recruitment of survivors to the breeding stock, to influence pup production. But whatever its effect the population size in 1970 could not have been less than about $3,915(4.5 \times$ number of pups shot, see Table 1) and, adding the same proviso about the hunters taking an entire year class, was probably much higher.

Our population estimate is considerably larger than the maximum number of seals counted hauled out together $(1,722$ on July 17,1969$)$. Juvenile Common Seals from the Wash have been reported from the Forth estuary to the French coast in tag recoveries. If they occur on any appreciable scale, these movements from the area, perhaps to feed, would mean that a proportion of the total stock was missing from the

Wash haul-outs at any particular time. Local population 'explosions' at places such as nearby Donna Nook, Blakeney and Scroby Sands cause alarm among drift-net fishermen but last for a few days only and suggest that such feeding migration often occur.

The Common Seal in the Wash is clearly not on the verge of extinction as some reports have claimed. In the early 1970 s there was a conviction among biologists and seal hunters alike that the heavy exploitation of the Common Seal in Shetland, where around $90 \%$ of the annual pup production was taken, would irreversibly reduce the stock if allowed to continue. Consequently a complete ban on Common Seal hunting in Shetland was implemented in 1973. The level of exploitation in the Wash has never reached this high figure. Nevertheless, the provisions of the 1970 Act allowed the introduction of a more restricted hunting regime. The quota was set at 400 pups in 1971, compared with an average of over 700 a year in the six-year period immediately preceding the passage of the Act. The current legislation provides a flexible means of applying controls as they are needed and as long as there is a programme of continuous monitoring, the stock in the Wash should not be at risk.

Table 1 Capture-recapture data and estimates of pup production

\begin{tabular}{lcccc}
\hline Year & $\begin{array}{c}\text { No. of tags } \\
\text { applied }\end{array}$ & $\begin{array}{c}\text { No. of tags } \\
\text { in catch }\end{array}$ & $\begin{array}{c}\text { Size of } \\
\text { catch }\end{array}$ & $\begin{array}{c}\text { Estimate of } \\
\text { pup production }\end{array}$ \\
1968 & 37 & 12 & 459 & 1,309 \\
1970 & 39 & 22 & 870 & 1,419 \\
1971 & 174 & 27 & 303 & 1,900 \\
1972 & 111 & 35 & 380 & 1,175 \\
1973 & 193 & 36 & 380 & 1,987 \\
\hline
\end{tabular}

